\title{
Calculation of track component failure caused by the most dangerous defects on change of their design and operational conditions
}

\author{
Boris Glusberg, ${ }^{1,}$, , Vadim Korolev², Irina Shishkina ${ }^{2}$, Aleksei Loktev $^{2}$, Jalil Shukurov $^{2}$, Pavel \\ Geluh $^{2}$ and Daniil Loktev ${ }^{3}$ \\ ${ }^{1}$ JSC Railway Research Institute (JSC VNIIZhT), 3rd Mytischinskaya str., 10, Moscow, 129626, Russia \\ ${ }^{2}$ Moscow State University of Railway Engineering, 22/2 Chasovaya str., Moscow, 125993, Russia \\ ${ }^{3}$ Moscow State University of Civil Engineering (MGSU), Yaroslavskoye Shosse, 26, Moscow, 129337, \\ Russia
}

\begin{abstract}
The article considers a calculation method of track component failure resulting from high-level bending stresses caused by the movement of the rolling stock. The method is based on the probabilistic nature of stress value in components, as well as statistic data on the fatigue properties of the metal from which they are made. The method is approved by the calculation example of the most dangerous failure types of turnout components but it can find a wider application. By using this method, the evaluations of failure change can be obtained for all design components that carry a cyclic load on change of their operation conditions.
\end{abstract}

\section{Introduction}

The most dangerous failure type of trackform components are cracks and fractures of rails, switch blades, crossings and fastening elements resulting from high-level bending stresses arising from the train load [1-3].

Railway infrastructure experts are constantly carrying out a development of reduction in structural vulnerability caused by dangerous defects [4-6].

The computational algorithm is used for an operational evaluation of proposals aimed at a failure reduction as related to the defects, as well as for an assessment of the impact on a number of changing operational conditions. What is more, it is useful that this algorithm would allow to calculate in respect of the probabilistic aspect by providing not mean value, but the failure distribution of a component in dependence to the lifelength.

\section{Methods}

The necessary algorithm can be constructed using the principle of damage summation and the fatigue calculation procedure adopted in mechanical engineering.

The fatigue dependence equation is often used in fatigue calculations as follows:

\footnotetext{
*Corresponding author: shishkinaira@inbox.ru
} 


$$
\sigma_{i}^{m} \cdot N_{i}\left(\sigma_{i}\right)=\left\{\begin{array}{ll}
\sigma_{i}^{m} \cdot N_{0}, & \sigma_{i} \geq \sigma_{r} \\
\infty, & \sigma_{i}<\sigma_{r}
\end{array}\right\}
$$

where $\mathrm{m}$ is the fatigue dependence index;

$\sigma_{r}$ is the long-time strength at a cycle asymmetry coefficient equal to $r$;

$N_{0}$ is the number of cycles corresponding to the break point on the fatigue curve;

$\sigma_{i}$ is the stress amplitude under consideration;

$N_{i}\left(\sigma_{i}\right)$ is the number of cycles before the fatigue crack initiation at the amplitude $\sigma_{i}$.

From equation (1) it is possible to determine the number of cycles that the component can withstand before the fatigue crack initiation.

If the stress cycles with different amplitudes arise in the trackform component during its operation, then the number of cycles that it can withstand before the fatigue crack initiation, can be defined by means of the principle of damage summation by a straight-line or corrected straight-line theory [2]:

$$
n_{0}=\frac{a}{\int_{\sigma_{p o v}} \frac{p_{\sigma}(\sigma)}{N(\sigma)} d \sigma}
$$

where $n_{0}$ is the number of cycles before the fatigue crack initiation in the component;

$p(\sigma)$ is the density of stress amplitude distribution;

$N(\sigma)$ is the number of cycles before the fatigue crack initiation at every particular value of the cycle amplitude $\sigma$ (it can be obtained from (1));

$a$ is the unit of the straight-line theory and $0,1 \div 2,0$ are for the corrected theory;

$\sigma_{\text {pov }}$ means the detrimental stress summation.

We shall introduce a concept of equivalent stresses to simplify the further reasoning. Equivalent stresses are such constant stress amplitudes where a component withstands as many stress cycles as at the full spectrum of amplitude variations $p(\sigma)$, occurring during the operating. Then it follows from the fatigue dependence equation:

$$
n_{0}=\frac{\sigma_{r}^{m} \cdot N_{0}}{\sigma_{e c v}}
$$

By making (2) equal to (3) we shall obtain:

$$
\sigma_{e c v}=\left(\sigma_{r}^{m} \cdot N_{0} \cdot \int_{\sigma_{p o v}} \frac{p_{\sigma}(\sigma)}{N(\sigma)} d \sigma\right)^{1 / m}
$$

We can express $N(\sigma)$ from (1) and plug in (4), and then by collecting similar terms we shall obtain:

$$
\sigma_{e c v}=\left(\int_{\sigma_{p o v}} p_{\sigma}(\sigma) \cdot \sigma^{m} d \sigma\right)^{1 / m}
$$

If equivalent stresses change as a result of a change in the operational conditions or the element design then a number of cycles that the element can withstand before the fatigue crack initiation, changes too, in this connection:

$$
n_{0(1)}=n_{0(2)}\left(\frac{\sigma_{2 e c v}}{\sigma_{1 e c v}}\right)^{m}
$$

where $\sigma_{1 e c v}$ and $\sigma_{2 e c v}$ are the equivalent stresses for two different operation conditions or element designs;

$n_{0(1)}=n_{0(2)}$ is the lifelength before the crack initiation.

Plugging (5) and (6) we get: 


$$
n_{0(1)}=n_{0(2)}\left(\int_{\sigma_{p o v}} p_{\sigma(2)}(\sigma) \cdot \sigma^{m} d \sigma / \int_{\sigma_{p o v}} p_{\sigma(1)}(\sigma) \cdot \sigma^{m} d \sigma\right)
$$

The dependence (7) can be used for impact assessment of structural changes or operational conditions on the failure distribution and changes of the bending stress distribution. The spread of the component lifelength arising during operation before the initiation of fatigue cracks is accounted for by the load parameter spread forming a distribution $p(\sigma)$, as well as by the strength characteristic spread.

The above equivalent stresses are the result of convolutions of the stress distribution $p(\sigma)$, they are constant for a particular design and operation conditions of the component. Therefore, when we consider the fatigue dependence at coordinates $\left\{\sigma_{e c v}, N\right\}$, then the failure distribution as related to component lifelength can only be determined by the spread of component strength characteristics relating to the manufacturing quality and the parameters of the material from which it is made.

It has been known that every fatigue curve corresponds to a certain probability of the fatigue dependence [7]. The most frequently used curves are with a probability of 0.5 . If we use the fatigue curves with a different probability, then it is possible to obtain the failure distribution with the same stress depending on the strength parameters of the metal from which the component is made. What is more, if the stress amplitudes are constant then the probability for each specific value of life length $\mathrm{N}$ will correspond to the probability of fatigue curve and conversely, the fatigue curve of the same probability $p_{N}\left(N_{i}\right)$ will correspond to the probability $p_{N}\left(N_{i}\right)$, of the crack initiation after lifelength $\mathrm{Ni}$ during operation.

All this will be related to the fatigue dependences at coordinates $\left\{\sigma_{e c v}, N\right\}$. Since $\sigma_{e c v}$ are fixed for a particular design and its operation conditions, the fatigue dependences with a probability $p_{N}\left(N_{i}\right)$. will correspond to each vector $\left\{\sigma_{i e c v}, N_{i}\right\}$.

By the use of this fatigue dependence it is possible to determine a new lifelength value before the crack initiation $N_{2}$ for new values $\sigma_{\text {ecv (nov) }}$ according to the formulas (6) or (7), the probability of this lifelength value $p_{\text {novN }}\left(N_{2}\right)$ will correspond to the probability of the fatigue $\operatorname{crack} p_{\text {starN }}\left(N_{1}\right)$. By the use of the formula (7) we obtain for every equivalent stress relation:

$$
p_{N(\text { nov })}\left(n_{0(2)}\right)=p_{N(\text { star })}\left(n_{0(1)}\right)
$$

or by expressing $n_{0}$ from (7) we get:

$$
p_{N(n o v)}\left(n_{0}\right)=p_{N(\text { star })}\left[n_{0}\left(\int_{\sigma_{\text {pov }}} p_{\sigma(2)}(\sigma) \cdot{\sigma_{2}}^{m} d \sigma / \int_{\sigma_{p o v}} p_{\sigma(1)}(\sigma) \cdot \sigma_{1}{ }^{m} d \sigma\right)\right]
$$

Thus, in order to obtain the lifelength distribution before the crack initiation in some changed operation conditions (or for a changed design) of the turnout component it is enough to know the lifelength distribution for some particular operation conditions and to have the data on the bending stress amplitude distribution under the conditions in which the lifelength distribution in some changed operation conditions (or for a changed design) is known.

After the lifelength integration (9) we can obtain the dependence of component failure accumulation from bending stresses:

$$
P(N)=\int_{0}^{N} P_{N}(N) \cdot d N
$$

The dependences (8), (9) and (10) provide a computational algorithm to estimate changes in the failure distribution that can result from the high-level bending stresses depending on changes of operation conditions and the design of the turnout component. 


\section{Results}

We consider applying the developed algorithm by the example of the evaluation of improvement of P65 crossings. Figure 1 shows the distribution of the accumulated crossing failure with an old tail-end design (continuous line). Utilizing Bartlett's test it is easy to show that the distribution of the crossing failure throughout the tail-end defects is exponential with a probability of $0,96 \div 0,97$ and the parameter $\theta=66.0$ GMT.

In Figure 1 the points (circles) are located corresponding to the exponential distribution $F=1-\exp \left(-\frac{T}{66}\right)$. Even without special evaluations, they show that the exponential distribution brings into proximity with the natural one.

This study [8] shows that the strengthening of P65 crossing tail-end leads to a bending stress decrease by $17 \%$ in the foot at the most loaded section (from $120 \mathrm{MPa}$ to $100 \mathrm{MPa}$ during the pulsator testing with the same load).

Since the structural change of tail-end foot has a slight impact on the level of dynamic forces acting on the crossing during the passage of train vehicle units, it can be assumed that, all things being equal, the relation between the bending stresses for new and old designs of tail-end crossings can remain in the track. Then the track stress distribution for a new design can be found from the distribution for an old design by using variate transformation rules [9].

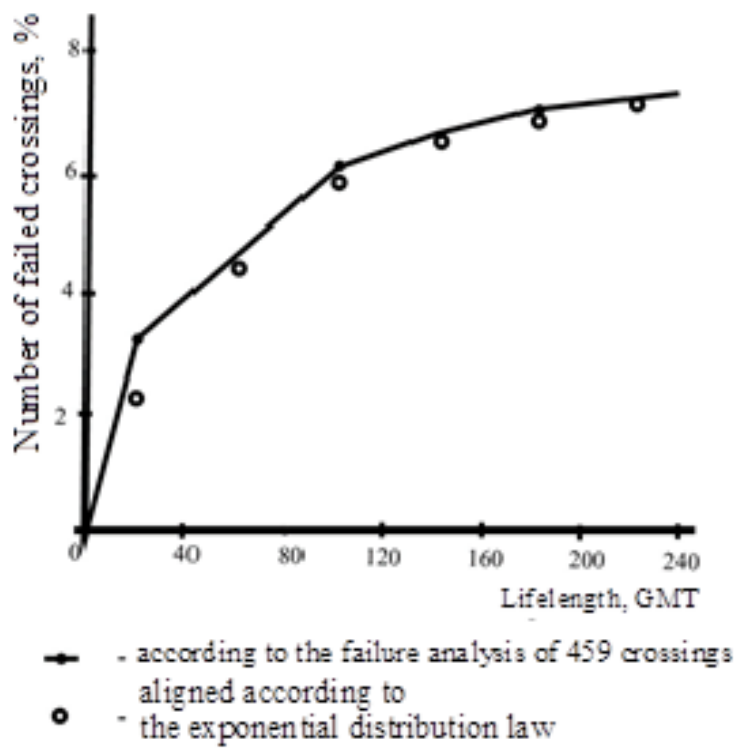

Fig. 1. Accumulated crack failures of crossings in the tail-end. 


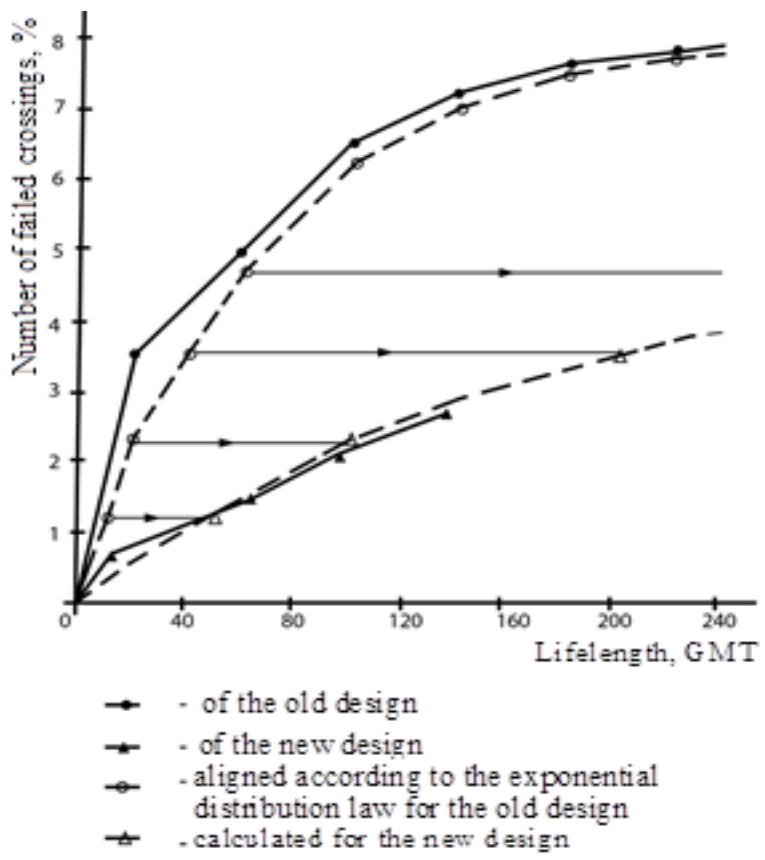

Fig. 2. Accumulated failures of $\mathrm{P} 65$ crossing, type 1/11, of the old and strengthened design caused by cracks in the tail-end.

Let us assume that

$$
\sigma_{\text {nov }}=k \cdot \sigma_{\text {star }}
$$

where $k$ is the coefficient of the stress change on change of tail-end design.

The transformation formula is given by:

$$
p_{\sigma(\text { nov })}(\sigma)=p_{\sigma(\text { star })}\left[\sigma_{\text {star }}\left(\sigma_{\text {nov }}\right)\right]_{\sigma} \cdot|J|_{\sigma_{\text {nov }}=\sigma}
$$

where $J$ is the Jacobian of the transformation.

Plugging (11) in (12) we get:

$$
p_{\sigma(\text { nov })}(\sigma)=k \cdot p_{\sigma(\text { star })}^{\sigma}\left(\frac{\sigma}{k}\right)
$$

Taking into account (9) we obtain:

$$
p_{N(\text { nov })}(N)=p_{N(\text { star })}\left[N \cdot k\left(\int_{\sigma_{\text {pov }}} p_{\sigma(\text { star })}\left(\frac{\sigma}{k}\right) \cdot \sigma^{m} d \sigma / \int_{\sigma_{\text {pov }}} p_{\sigma(\text { star })}(\sigma) \cdot \sigma^{m} d \sigma\right)\right]
$$

Plugging (14) in (10) we can obtain an integral failure curve.

The results of the calculations by formula (10) with consideration of (14) for crossings are shown in Figure 2 (the dashed line with open triangles). By comparison, the analogical dependence is shown according to the operational results of crossings (the dashed line with open triangles).

As the Figure 2 shows, there is a good convergence of design and operating data. This confirms the feasibility of using the assumed computational algorithm.

The dependence received allows extrapolating and interpolating the data pertaining to the failure of a new crossing design caused by the tail-end defects and thus it makes possible to assess the strengthening effect. 
It's easy to see from Figure 2 that about 2 per cent of the strengthened crossings are expected to fail throughout the tail-end defects at the time of the lifelenght of 85 GMT. This is 2.35 times smaller than that for the crossings of the old design.

\section{Conclusions}

By analogy with the above calculation of crossing failure with a changed design, we can carry out calculations for rails, switch blades, crossings and fastening components on change of their geometrical characteristics and operational conditions, e.g. axial load or traverse speed [10].

\section{References}

1. A.Yu. Abdurashitov, B.E. Glyuzberg, V.V. Korolev, Klassifikator defektov $i$ povrezhdeniy elementov strelochnykh perevodov, OAO "RZHD" (TSentr "transport", Moscow, 2012)

2. V.V. Korolev, Put' i putevoye khozyaystvo 8, 13-16 (2013)

3. V.V. Korolev, Put' i putevoye khozyaystvo 7, 14-16 (2016)

4. B.E. Glyuzberg, N.V. Zverkova, V.V. Korolev, I.V. SHishkina, Put' i putevoye khozyaystvo 2, 20-22 (2018)

5. V.V. Korolev, V.A. Mal'tsev Vnedreniye sovremennykh konstruktsiy i tekhnologiy v putevoye khozyaystvo, Sb. mat. 7-oy n.-t. konf. MGUPS MIIT, 45-52 (2014)

6. V.V. Korolev, I.V. SHishkina, Vnedreniye sovremennykh konstruktsiy i tekhnologiy v putevoye khozyaystvo, Sb. mat. 9-oy n.-t. konf. MGUPS MIIT, 188-193 (2016)

7. V.P. Kogayev, Raschety na prochnost' pri napryazheniyakh peremennykh vo vremeni (1977)

8. V.I. SHakhov, N.N. Putrya, M.I. Titarenko, B.A. Ballenkov, Vestnik VNIIZHT 6, $42-$ 44 (1983)

9. Yu.A. Rozanov, Sluchaynyye protsessy (1971)

10. A. Loktev, V. Korolev, I. Shishkina, D. Basovsky, Transportation Geotechnics and Geoecology, TGG 2017, 133 - 137 (2017) 